\title{
Implementasi Quantum Teaching Pada Pembelajaran Tematik Kelas V MI Mambaul Ulum Kandangrejo
}

\author{
Faiqotul Isma Azizah \\ UIN Kiai Haji Achmad Siddiq Jember \\ faiqisma07@gmail.com \\ Hartono \\ UIN Kiai Haji Achmad Siddiq Jember \\ hartono2986@gmail.com \\ DOI: 10.35719/educare.v2i2.67
}

\begin{abstract}
The Quantum Teaching learning model is a modification of the various interactions that exist in and around the moment in learning. This study aims to find out more about how to apply Quantum Teaching in measuring students' abilities including cognitive, affective and psychomotor aspects. This research method uses qualitative research methods with the type of research field research. Data collection techniques using observation techniques, interviews, and documentation. While the data analysis is a qualitative analysis model of Miles and Huberman and Saldana which consists of data collection, data condensation, data presentation and drawing conclusions. The results of this study are: (1) Implementation of Quantum Teaching in Class V Thematic Learning at MI Mambaul Ulum Kandangrejo cognitive aspects, namely students are able to think more critically and broadly, students are able to do assignments or exercises and can understand learning well, students able to provide questions and answers properly and appropriately. (2) Implementation of Quantum Teaching in Class V Thematic Learning at MI Mambaul Ulum Kandangrejo aspects in the affective aspect, namely: the curiosity of students increases, students become more focused, students' attitudes become more confident and courageous. (3) Implementation of Quantum Teaching in Class V Thematic Learning at MI Mambaul Ulum Kandangrejo psychomotor aspects, namely: students are able to practice well the learning media is provided, students are able to name the names and parts of the circulatory organs, students are able to show the circulatory organs blood using the medium.
\end{abstract}

Keywords: Quantum Teaching; Learning; Madrasah Ibtidaiyah 


\begin{abstract}
Abstrak
Model pembelajaran Quantum Teaching merupakan pengubahan bermacammacam interaksi yang ada di dalam dan di sekitar momen dalam pembelajaran. Penelitian ini bertujuan untuk mengetahui lebih dalam bagaimana penerapan Quantum Teaching dalam mengukur kemampuan peserta didik meliputi aspek kognitif, afektif dan psikomotorik. Metode penelitian ini menggunakan metode penelitian kualitatif dengan jenis penelitian Field Research. Teknik pengumpulan data menggunakan teknik observasi, wawancara, dan dokumentasi. Sedangkan analisis data analisis kualitatif model Miles dan Huberman dan Saldana yang terdiri dari pengumpulan data, kondensasi data, penyajian data dan penarikan kesimpulan. Hasil penelitian ini yaitu: (1) Implementasi Quantum Teaching Pada Pembelajaran Tematik Kelas V di MI Mambaul Ulum Kandangrejo aspek kognitif yaitu peserta didik mampu berfikir secara lebih kritis dan luas, peserta didik mampu mengerjakan tugas atau latihan dan dapat memahami pembelajaran dengan baik, peserta didik mampu memberikan pertanyaan dan jawaban dengan baik dan sesuai. (2) Implementasi Quantum Teaching Pada Pembelajaran Tematik Kelas V di MI Mambaul Ulum Kandangrejo aspek dalam aspek afektif yaitu: rasa ingin tahu peserta didik meningkat, peserta didik menjadi lebih fokus, sikap peserta didik semakin percaya diri dan berani. (3) Implementasi Quantum Teaching Pada Pembelajaran Tematik Kelas V di MI Mambaul Ulum Kandangrejo aspek dalam aspek psikomotorik yaitu: peserta didik mampu mempraktikkan dengan baik media pembelajaran disediakan, peserta didik mampu menyebutkan nama dan bagian organ peredaran darah, peserta didik mampu menunjukkan bagian organ peredaran darah dengan menggunakan media.
\end{abstract}

Kata Kunci: Quantum Teaching; Pembalajaran; Madrasah Ibtidaiyah

\title{
PENDAHULUAN
}

Pendidikan dalam Undang-Undang Sistem Pendidikan Nasional No.

20 tahun 2003. Bab II pasal 3 ayat 1 menegaskan:

Pendidikan Nasional berfungsi mengembangkan kemampuan dan membentuk watak serta peradaban bangsa yang bermartabat dalam rangka mencerdaskan kehidupan bangsa bertujuan untuk berkembangnya potensi peserta didik agar menjadi manusia beriman dan bertaqwa kepada Tuhan Yang Maha Esa, berakhlak mulia, sehat, berilmu cakap, kreatif, 
mandiri dan menjadi warga negara yang demokratis serta bertanggungjawab. ${ }^{1}$

Pendidikan di sekolah secara otomatis memerlukan proses pembelajaran. Pembelajaran pada hakikatnya sangat terkait dengan bagaimana membangun interaksi yang baik antara dua komponen, yaitu guru dan peserta didik. Interaksi yang baik dapat digambarkan dengan suatu keadaan dimana guru dapat membuat peserta didik belajar dengan mudah dan terdorong untuk mempelajari materi pembelajaran. Selama proses pembelajaran setidaknya terdapat tiga komponen utama yang saling berpengaruh, yaitu kondisi pembelajaran, model pembelajaran dan hasil pembelajaran. $^{2}$

Terkait dengan masalah tersebut Al-Qur'an telah memberikan petunjuk mengenai metode pendidikan secara umum, sebagaimana tersirat jelas didalam Al-Quran Allah berfirman:

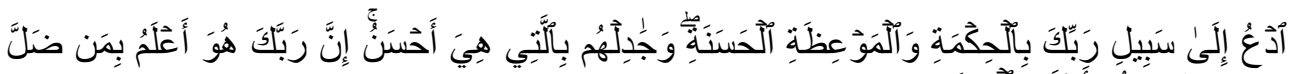

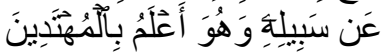

Artinya: "Serulah (manusia) kepada jalan Tuhan-mu dengan hikmah dan pelajaran yang baik dan bantahlah mereka dengan cara yang baik. Sesungguhnya Tuhanmu Dialah yang lebih mengetahui tentang siapa yang tersesat dari jalan-Nya dan Dialah yang lebih mengetahui orang-orang yang mendapat petunjuk" (QS. An-Nahl: $125)^{3}$

Dari ayat di atas dapat diambil kesimpulan bahwa guru dalam memberikan suatu pembelajaran harus dengan cara yang baik yaitu dengan memudahkan peserta didik untuk bisa belajar sesuai dengan kemampuan yang dimiliki oleh setiap peserta didik. Seorang pendidik tidak boleh mementingkan materi atau bahan ajar harus tercapai dengan mengorbankan peserta didik. Sebaliknya dapat mengusahakan dengan jalan menyusun

\footnotetext{
${ }^{1}$ Sekertariat Negara RI, Undang-Undang System Pendidikan Nasional (Jakarta: Sinar Grafika, 2016), 7.

${ }^{2}$ Taufiqur Rahman, Aplikasi Model-model Pembelajaran (Semarang: CV. Pilar Nusantara, 2018), 47.

${ }^{3}$ Tim Tashih Departemen Agama. Al-Qur'an dan Tafsirnya Jilid VII. (Medan: PT Dana Bhakti Wakaf, 1995), .
} 
materi pembelajaran tersebut dengan sedemikian rupa sehingga sesuai dengan taraf kemampuan mereka serta dengan gaya yang menarik.

Pembelajaran tematik sangat penting diterapkan di sekolah dasar atau madrasah ibtidaiyah, sebab model pembelajaran ini memiliki banyak nilai dan manfaat, diantaranya: (1) peserta didik dapat melihat hubunganhubungan yang bermakna sebab isi/materi pembelajaran lebih berperan sebagai sarana atau alat, bukan tujuan akhir, (2) pembelajaran tidak terpecah-pecah karena peserta didik dilengkapi dengan pengalaman belajar yang lebih terpadu, (3) memberikan penerapan-penerapan dari dunia nyata sehingga dapat mempertinggi kesempatan transfer belajar. ${ }^{4}$

Selanjutnya, pembelajaran Quantum Teaching yaitu mengubah bermacam-macam interaksi yang ada di dalam kegiatan pembelajaran. Maka dari itu guru harus tahu apa yang ada pada peserta didiknya dan harus ada kerjasama yang solid antara guru dengan peserta didik. Dalam pelaksanaan Quantum Teaching lebih menekankan pada tingkat emosional anak. Maka Quantum Teaching mempunyai asas "bawalah dunia mereka ke dunia kita dan antarkan dunia kita ke dunia mereka".Inilah asas utama yang dimiliki oleh Quantum Teaching. ${ }^{5}$

Model pembelajaran Quantum Teaching merupakan salah satu model pembelajaran yang diterapkan di beberapa lembaga formal tertentu dalam proses belajar pembelajaran dengan hasil yang memuaskan sebab dalam pembelajaran Quantum Teaching memberikan kesempatan dan pengalaman pada peserta didik untuk dapat merasakan indahnya penemuan hal-hal baru. ${ }^{6}$

Pembelajaran Quantum Teaching pelaksanaannya adalah pendidik harus mampu mengkondisikan peserta didik atau melibatkan mereka untuk berfikir dengan menumbuhkan ide-ide cemerlang, membuat mereka

\footnotetext{
${ }^{4}$ Sumining. "Pengembangan Bahan Ajar Tematik Berbasis Nilai-Nilai Keislaman Kelas VI Madrasah Ibtidaiyah ”. EDUCARE: Journal of Primary Education 2, no. 1 (2021), 3-4.

${ }^{5}$ Bobbi De Porter, dkk, Mempraktikkan Quantum Teaching, (Bandung: Kaifa, 2000), 7.

${ }^{6}$ Bobbi DePorter, dkk, Mempraktikkan Quantum Teaching di Ruang-Ruang Kelas (Bandung: Mizan Media Utama, 2008), 5.
} 
bertanya "apa manfaatnya bagiku“. Pembelajaran Quantum Teaching merupakan penyelesaian dari pendekatan yang bersifat pengoptimalan potensi yang dimiliki oleh anak manusia yang harus dirangsang dengan rasa nyaman dan percaya diri, serta peningkatan prestasi belajar untuk memunculkan motivasi dalam diri peserta didik.

Pemilihan pembelajaran menggunakan Quantum Teaching ini salah satu alternatif dalam menggunakan metode pembelajaran tematik dapat memberikan perubahan pola fikir baik yang bersifat individual maupun kepekaan sosial. Dalam pembelajaran Quantum Teaching terkandung bermacam-macam metode pengajaran yang diolah menjadi satu seperti metode ceramah, tanya jawab, demonstrasi, karya wisata, penugasan, pemecahan masalah, diskusi, eksperimen, penemuan dan proyek.

Dalam proses pembelajaran peserta didik cenderung tidak mau bertanya kepada guru meskipun mereka sebenarnya belum mengerti tentang materi yang disampaikan oleh guru. Kondisi seperti ini menyebabkan guru kesulitan dalam menyampaikan materi. Hal tersebut terjadi pada seluruh mata pelajaran termasuk juga dalam pembelajaran tematik. ${ }^{7}$

Sistem pembelajaran duduk tenang, mendengarkan informasi dari guru sepertinya sudah membudaya sejak dulu, sehingga untuk mengadakan perubahan ke arah pembelajaran yang aktif, kreatif, menyenangkan agaknya masih sulit. Guru masih dominan dan peserta didik resisten, guru masih menjadi pemain dan peserta didik penonton, guru aktif dan guru pasif. Hal ini juga dibuktikan oleh peserta didik kelas V MI Mambaul Ulum Kandangrejo, ketika kegiatan pembelajaran berlangsung ada beberapa peserta didik yang bercerita, bermain sendiri dan berbicara sendiri dengan teman lainnya yang tidak ada kaitannya dengan materi pelajaran. ${ }^{8}$ Untuk memperbaiki mutu dan kualitas pembelajaran yang membosankan, maka pada pelaksanaanya dapat menerapkan berbagai model pembelajaran. Salah

${ }^{7}$ Sunarti, Wawancara, Jember, 24 September 2020.

${ }^{8}$ Observasi di MI Mambaul Ulum Kandangrejo Kelas V, 24 September 2020. 
satunya adalah melalui model Quantum Teaching. Model Quantum Teaching peserta didik akan diajak belajar dalam suasana yang lebih nyaman dan menyenangkan.

Model Quantum Teaching ini sudah diterapkan oleh guru tematik kelas V di MI Mambaul Ulum Kandangrejo. MI Mambaul Ulum Kandangrejo sebagai salah satu madrasah swasta favorit di Desa Sukoreno. Sistem pembelajaran di madrasah ini dilakukan di dalam dan di luar kelas, dalam proses pembelajaran di dalam kelas guru tematik khususnya kelas V di MI Mambaul Ulum Kandangrejo selalu berusaha membuat pembelajaran yang menarik.

MI Mambaul Ulum Kandangrejo menerapkan model Quantum Teaching dalam pembelajaran tematik. Dalam hal ini, penerapan quantum teaching, guru mengkombinasikan metode ceramah dengan diskusi dalam model pembelajarannya, karena dapat membuat situasi pembelajaran menjadi lebih menarik, bermakna dan dapat memicu keaktifan peserta didik. Menurut Bobbi DePorter Quantum Teaching Quantum Teaching adalah pengubahan belajar yang meriah, dengan segala nuansanya. Quantum Teaching juga menyertakan segala kaitan, interaksi, dan perbedaan yang memaksimalkan momen belajar. Quantum Teaching berfokus pada hubungan dinamis pada lingkungan kelas, interaksi yang mendirikan landasan dan kerangka untuk belajar. ${ }^{9}$ Oleh karena itu dengan diterapkannya model Quantum Teaching di MI Mambaul Ulum Kandangrejo dianggap mampu membuat pembelajaran lebih bermakna terhadap peserta didik.

\section{METODE PENELITIAN}

Penelitian ini merupakan penelitian dengan menggunakan pendekatan kualitatif dengan jenis penelitian Field Research. Menurut Creswell mengatakan bahwa penelitian lapangan merupakan penelitian tentang

\footnotetext{
${ }^{9}$ Nandang Kosasih dan Dede Sumana, Pembelajaran Quantum dan Optimalisasi Kecerdasan (Bandung: Alfabeta, 2013), 92.
} 
sebuah konteks yang dilakukan oleh individu di dalam masyarakat yang diceritakan oleh mereka sendiri atau orang lain yang menyaksikan konteks tersebut. ${ }^{10}$ Penentuan subjek penelitian yang digunakan adalah Purposive yaitu teknik penentuan informan yang diplih dengan pertimbangan dan tujuan tertentu atau seleksi khusus. Sehingga dalam penelitian ini hanya dipilih informan yang dipandang mengetahui betul tentang aspek yang akan dikaji dalam penelitian ini.

Teknik pengumpulan data dalam penelitian ini menggunakan teknik observasi, wawancara, dan dokumentasi dengan analisis data analisis kualitatif model Miles dan Huberman dan Saldana yang terdiri dari pengumpulan data, kondensasi data, penyajian data dan penarikan kesimpulan.

\section{HASIL DAN PEMBAHASAN TEMUAN}

\section{Implementasi Quantum Teaching Pada Pembelajaran Tematik Kelas V}

\section{Dalam Aspek Kognitif}

Berdasarkan hasil temuan melalui observasi, wawancara dan dokumenetasi bahwa MI Mambaul Ulum Kandangrejo menerapkan model pembelajaran Quantum Teaching dalam aspek kognitif dengan menggunakan metode mengajar ceramah, diskusi, dan tugas seperti yang dijelaskan oleh Nana Sudajana tentang model pembelajaran ${ }^{11}$.

Penggunaan ketiga jenis ini metode mengajar ini dapat dilakukan dengan diawali pemberian informasi kepada peserta didik tentang materi atau bahan yang akan didiskusikan oleh peserta didik, lalu memberikan masalah untuk didiskusikan, kemudian diikuti dengan tugas-tugas yang harus dilakukan peserta didik. Ceramah dimaksudkan untuk memberikan penjelasan atau informasi mengenai bahan yang akan dibahas dalam diskusi sehingga diskusi dapat berjalan dengan baik sesuai dengan tujuan yang

10 Dede Rosyada, Penelitiian Kualitatif Untuk Ilmu pendidikan (Jakarta: Kencana, 2020), 48.

${ }^{11}$ Nana Sudjana, Dasar-Dasar Proses Belajar Mengajar, (Bandung: SB Algensindo, 2019) 92. 
hendak dicapai. Pada akhir kegiatan diskusi, peserta didik diberikan beberapa tugas yang harus dikerjakan untuk mengetahui hasil yang dicapai peserta didik melalui diskusi tersebut. Jenis kegiatan yang dilakukan dapat dilihat dalah tabel sebagai berikut:

Jenis Kegiatan Belajar Mengajar ${ }^{12}$

\begin{tabular}{|c|c|c|}
\hline No & Langkah & Jenis Kegiatan Belajar Mengajar \\
\hline 1 & Persiapan & $\begin{array}{l}\text { a. Mempersiapkan kondisi belajar peserta didik } \\
\text { b. Memberikan informasi atau penjelasan } \\
\text { tentang masalah tugas dalam diskusi } \\
\text { (ceramah) } \\
\text { c. Mempersiapkan sarana atau prasarana untuk } \\
\text { melakukan diskusi (tempat, peserta didik, } \\
\text { dan waktu) }\end{array}$ \\
\hline 2 & Pelaksanaan & $\begin{array}{l}\text { a. Peserta didik melakukan diskusi: } \\
\text { 1. Guru merangsang seluruh peserta didik } \\
\text { berpartisipasi dalam diskusi. } \\
\text { 2. Memberikan kesempatan kepada semua } \\
\text { peserta didik untuk aktif } \\
\text { 3. Mencatat tanggapan atau saran dan ide- } \\
\text { ide-ide yang penting }\end{array}$ \\
\hline 3 & $\begin{array}{l}\text { Evaluasi/ } \\
\text { tindak lanjut }\end{array}$ & $\begin{array}{l}\text { a. Memberi tugas kepaa peserta didik untuk: } \\
\text { 1. Kesimpulan diskusi } \\
\text { 2. Mencatat hasil diskusi } \\
\text { 3. Dan sebagainya }\end{array}$ \\
\hline
\end{tabular}

untuk meningkatkan kemampuan peserta didik dalam aspek koginitif dan menggunakan pendekan metafora sesuai dengan pernyataan DePorter yaitu penyajian materi dengan Metafora dalam pembelajaran memiliki peranan penting untuk meningkatkan minat dan motivasi belajar peserta didik, karena pendekatan Metafora akan membawa peserta didik ke dalam suasana yang penuh kegembiraan dan keharuan, kondisi ini menciptakan pemaknaan dalam proses belajar selanjutnya. ${ }^{13}$

\footnotetext{
${ }^{12}$ Nana Sudjana, Dasar-Dasar Proses Belajar Mengajar, 93.

${ }^{13}$ DePorter, Quantum Teaching Mempraktikkan Quantum Learning di Ruang-ruang Kelas, (Bandung; Kaifa, 2000), 145.
} 
Bentuk-bentuk pendekatan Metafora dijelaskan oleh Suherman dan Sapa at antara lain: (1) Bercerita dengan menggunakan perumpaan untuk menumbuhkan kesadaran betapa pentingnya pelajaran yang akan dipelajari. (2) Bercerita dengan perumpamaan tentang sebuah tanggung jawab diri sendiri. (3) Memberikan penjelasan bagaimana kiat meraih sukses dalam proses pembelajaran. (4) Menyajikan paparan bahwa orang belajar harus siap keluar dari zona nyaman. (5) Mendiskusikan tentang pembelajaran yang akan dipelajari. (6) Mengisahkan tentang beberapa cerita. (7) Memberikan beberapa nasihat dan tips-tips untuk meraih keberhasilan belajar.

Hasil temuan penelitian relevan dengan teori yang dikemukakan diatas yaitu dilakukan dengan metode tandur, menggunakan metode mengajar cermah, diskusi dan penugasan dan kegiatan juga dilakukan dengan pendekatan metafora yaitu kegiatan pembelajaran dilakukan dengan kegiatan yang menyenangkan karena dengan seperti itu motivasi belajar peserta didik akan menjadi meningkat sehingga kemampuan peserta didik dalam aspekkognitif akan lebih baik lagi dan meningkat.

\section{Implementasi Quantum Teaching Pada Pembelajaran Tematik Kelas V Dalam Aspek Afektif}

Kemampuan peserta didik dalam aspek afektif berkaitanberkaitan dengan sikap, perasaan, emosi, nilai-nilai, aspirasi dan penyesuaian perasaan sosial. Untuk mengembangkan kemampuan peserta didik pada aspekafektif peserta didik dapat mengggunakan kunci dalam Quantum Teaching yaitu pendekatan perumpamaan.

Metode perumpamaan adalah suatu metode yang digunakan untuk mengungkapkan suatu sifat dan hakikat dari realitas sesuatu. Perumpamaan dapat dilakukan dengan menggambarkan sesuatu dengan sesuatu yang lain yang serupa, seperti mengumpamakan sesuatu yang rasional abstrak dengan sesuatu yang bisa diindera. Metode perumpamaan juga dapat 
diterapkanmelalui menciptakan gambar-gambar yang unik untuk menjelaskan sebuah konsep. ${ }^{14}$

Untuk memperoleh gambaran tentang kawasan tujuan instruksional afektif secara utuh, berikut ini akan dijelaskan setiap tingkat secara berurutan sebagai berikut: ${ }^{15}$

a. Tindakan menerima (receiving) yaitu proses pembentukan sikap dan perilaku dengan cara membangkitkan kesadaran tentang adanya stimulus tertentu yang mengandung estetika.

b. Tingkat tanggapan (responding) adalah segala perubahan perilaku organisme yang terjadi atau yang timbul karena adanya rangsangan.

c. Tingkat Karakterisasi (characterization) adalah sikap dan perbuatan yang secara konsisten dilakukan oleh seorang selaras dengan nilai-nilai yang dapat diterimanya, sehingga sikap dan perbuatan seolah-olah telah terjadi menjadi ciri-ciri pelakunya. ${ }^{16}$

Teori yang diatas relevan dengan data yang didapat dalam penerapan quantum teaching dalam aspek afektif, guru melakukan receiving dengan cara memotivasi peserta didik untuk membangkitkan sikap peserta didik dalam mengikuti pembelajaran dengan baik dan kondusif. Selanjutnya dalam respon peserta didik dapat menerima rangsangan sebuah motivasi yang diberikan oleh guru dengan segala perubahan sikap yang dimiliki peserta didik. Dalam characterization peserta didik dapat melakukan sikap yang konsisten dengan nilai-nilai yang sudah diberikan oleh guru.

Berdasarkan tiga tingkatan yang dirumuskan oleh Bloom dan Krathwool berkaitan dengan pengelompokkan aspek afektif menjadi dua tipe yang berbeda, yaitu: (a) Reflek yang terkondisi, yaiu reaksi pada stimulus khusus tertentu yang dilakukan secara spontasn tanpa direncanakan lebih dahulu tujuan reaksinya. (b) Sukarela (voluntary) adalah aksi dan

\footnotetext{
${ }^{14}$ DePorter, Quantum Teaching, 145.

${ }^{15}$ Hamdani, Strategi Belajar Mengajar,(Bandung: CV Pustaka Setia, 2011), 152.

${ }^{16}$ Hamdani, Strategi Belajar, 153.
} 
reaksi yang terencana untuk mengarahkan ke tujuan tertentu dengn cara membiasakan latihan-latihan untuk mengontrol diri. ${ }^{17}$

\section{Implementasi Quantum Teaching Pada Pembelajaran Tematik Kelas V Dalam Aspek Psikomotorik}

Berdasarkan hasil wawancara dan observasi yang dilakukan terkait dengan Quantum Teaching dalam meningkatkan kemampuan peserta didik pada aspek psikomotorik dengan strategi TANDUR yaitu Tumbuhkan pada tahapan ini guru merangsang peserta didik agar memiliki rasa ingin tahu yang tinggi dan dengan mengaktifkan indera penglihatan dan pendengaran.

Quantum Teaching memiliki lima prinsip atau kebenaran ketetapan. Seperti halnya asas utama, prinsp-prinsip ini juga mempengaruhi seluruh aspek Quantum Teaching. Prinsip-prinsip tersebut adalah sebagi berikut:

a. Segalanya berbicara: Segalanya dari lingkungan kelas hingga bahasa tubuh anda, dari kertas yang anda bagikan hingga rancangan pelajaran anda semua mengirim pesan tentang belajar.

b. Segala bertujuan: Semua yang terjadi dalam pengubahan anda mempunyai tujuan.

c. Pengalaman sebelum pemberian nama: Otak kita berkambang pesat dengan adanya rangsangan kompleks, yang akan menggerakkan rasa ingin tahu. Oleh karena itu, proses belajar paling baik terjadi ketika peserta didik telah mengalami informasi sebelum mereka memperoleh nama untuk apa yang merkea pelajari.

d. Akui setiap usaha: Belajar mengandung resiko. Berarti belajar melangkah keluar dari kenyamanan. Pada saat peserta didik mengambil langkah ini, mereka patut mendapat pengakuan atas kecakapan dan kepercayaan diri mereka.

\footnotetext{
${ }^{17}$ Hamdani, Strategi Belajar, 153.
} 
e. Jika layak dipelajari, maka layak pula dirayakan: Perayaan adalah sarapan pelajar juara. Perayaan memeberikan umpan balik mengenai kemajuan dan meningkatkan asosiasi emosi positif dengan belajar. ${ }^{18}$

Model pembelajaran Quantum Teaching menggunakan pendekatan sugestology yang pada prinsipnya sugesti dapat dan pasti mempengaruhi hasil situasi belajar. ${ }^{19}$ Quantum Teaching mencakup aspek-aspek penting dalam program neurolinguistik yaitu bagaimana otak mengatur informasi yang diperoleh dalam belajar, artinya dalam belajar peserta didik dan guru dapat meningkatkan motivasi, meningkatkan nilai belajar, memperbesar keyakinan diri, mempertahankan sikap positif dan melanjutkan keberhasilan dengan memanfaatkan keterampilan yang diperoleh. ${ }^{20}$

Hasil temuan dalam penelitian ini relevan dengan teori yang dikemukakan diatas yaitu penerapan Quantum Teaching untuk meningkatkan hasil belajar peserta didik pada aspek psikomotorik dilakukan dengan meningkatkan motivasi peserta didik sebelum proses pelaksanaan pembelajaran berlangsung, hal tersebut dilakukan agar peserta didik memiliki persepsi yang kuat dan semangat dalam pelaksanaan pembelajaran, serta memanfaatkan keterampilan yang ada pada setiap peserta didik yaitu dengan melihat modalitas yang ada pada peserta didik dan menjadikannya kekuatan agar anak dapat belajar sesuai dengan kemampuan dan keterampilan yang anak miliki. Kawasan psikomotorik adalah kawasan yang beriontasi pada keterampilan motorik yang berhubungan dengan anggota tubuh, atau tindakan (action) yang memerlukan koordinasi antara saraf dan otot.

Jadi dalam penelitian ini terdapat tiga fokus pemasalahan yang diteliti dan ditemukan data yang pertama penerapan Quantum Teaching dalam aspek afektif yaitu dapat meningkatkan motivasi peserta didik sebelum

\footnotetext{
${ }^{18}$ Bobbi DePorter, dkk, Mempraktikkan QuantumTeaching (Bandung: Kaifa,2000), 7-8.

${ }^{19}$ Sagala, Konsep dan Makna Pembelajaran, (Bandung: Alfabeta. 2008), 76.

${ }^{20}$ Bobbi DePorter, Quantum Teaching Mempraktikkan Quantum Learning di Ruangruang Kelas, (Bandung; Kaifa, 2000), 146.
} 
proses pelaksanaan pembelajaran berlangsung. Kedua adalah penerapan Quantum Teaching dalam aspek kognitif yaitu guru melihat aspek kognitif peserta didik dengan menunjuk beberapa peserta didik untuk mengerjakan latihan/soal. Ketiga adalah penerapan Quantum Teaching dalam aspek psikomotorik yaitu peserta didik dapat mempraktikkan materi yang telah dipelajari dengan baik.

\section{Rancangan Quantum Teaching Dalam Pembelajaran}

Dalam Quantum Teaching terdapat rancangan pengajaran yang dapat mewujudkan pembelajaran yang dinamis. Kerangka pengajaran tersebut dalam pelaksanaannya dilakukan dengan enam langkah yang tercermin dalam istilah TANDUR, yaitu:

a. Tumbuhkan

Pada awal kegiatan pembelajaran guru harus berusaha menumbuhkan atau mengembangkan minat peserta didik untuk belajar. Memberikan apersepsi yang cukup dan dapat dilakukan sehingga sejak awal kegiatan peserta didik telah termotivasi untuk belajar.

b. Alami

Ciptakan atau datangkan pengalaman umum yang dapat dimengerti semua peserta didik.

c. Namai

Setelah peserta didik melalui pengalaman belajar pada kompetensi dasar tertentu, kita ajak untuk menulis dikertas, menamai apa saja yang mereka peroleh, apakah informasi itu berupa gambar, tempat dan sebagainya kemudian mengajak mereka menempelkan hasilnya di papan tulis.

d. Demonstrasikan

Setelah peserta didik mengalami belajar akan sesuatu, beri kesempatan mereka untuk mendemonstrasikan kemampuaannya. Melalui pengalaman belajar peserta didik akan mengetahui dan mengerti bahwa dia memiliki pengetahuan dan informasi yang cukup memadai.

e. Ulangi 
Pengulangan dan post test memperkuat daya ingat dan dapat menumbuhkan rasa, "Aku tahu bahwa aku memang tahu ini."

f. Rayakan

Pengakuan untuk penyelesaian, partisipasi, dan pemerolehan keterampilan dan ilmu pengetahuan, bisa dilakukan dengan memberikan tepuk tangan maupun pemberian hadiah. ${ }^{21}$

Jadi, pembelajaran Quantum teaching ini tidak bersifat monoton sebab pembalajaran Quantum teaching bersifat dinamis dan bisa membuat peserta didik lebih bersemangat untuk belajar karena pembelajran Quantum teaching ini bisa memenuhi semua kebutuhan peserta didik dan tidak hanya menjadi pendengar setia guru tetapi peserta didik juga bisa mepraktikankan pengalamannya tersebut.

\section{Karakteristik Pembelajaran Quantum Teaching}

Pembelajaran Quantum Teaching memiliki karakteristik sebagai berikut: ${ }^{22}$

a. Pembelajaran Quantum Teachinglebih manusiawi, individu menjadi pusat perhatian, potensi diri, kemampuan berfikir, motivasi dan sebagainya.

b. Pembelajaran Quantum Teaching mensinergikan faktor potensi invidu dengan lingkungan fisik dan psikis dalam konteks pembelajaran. Dalam pandangan pembelajaran Quantum Teaching, faktor lingkungan dan kemampuan memiliki posisi yang sama-sama penting.

c. Pembelajaran Quantum Teaching memusatkan perhatian pada interaksi yang bermutu dan bermakna. Interaksi menjadi kata kunci dan konsep sentral dalam pembelajaran Quantum Teaching. Oleh karena itu, pembelajaran Quantum Teachingmemberikan tekanan pada pentingnya interaksi, frekuensi dan akumulasi interaksi yang bermutudan bermakna.

\footnotetext{
${ }^{21}$ Bobbi DePorter, 88.

${ }^{22}$ Nandang Kosasih dan Dede Sumana, 79-80.
} 
Dalam kata inilah faktor komunikasi menjadi sangat penting dalam pembelajaran Quantum Teaching.

d. Pembelajaran Quantum Teaching sangat menekankan kealamiahan dan kewajaran proses pembelajaran, bukan keadaan yang dibuat-buat.

e. Pembelajaran Quantum Teaching sangat menekankan kebermaknaan dan kebermutuan proses.

f. Pembelajaran Quantum Teaching memiliki model yang memadukan konteks dan isi pembelajaran.

g. Pembelajaran Quantum Teaching memusatkan perhatian pada pembentukan keterampilan akademis, keterampilan hidup dan prestasi fisikal atau material.

h. Pembelajaran Quantum Teaching menempatkan nilai dan keyakinan sebagai bagian penting proses pembelajaran. Misalnya, individu perlu memiliki keyakinan bahwa kesalahan atau kegagalan merupakan tanda bahwa ia belajar, kesalahan atau kegagalan bukan tanda bodoh atau akhir dari segalanya.

i. Pembelajaran Quantum Teaching mengutamakan keberagaman dan kebebasan, bukan keseragaman dan ketertiban

j. Pembelajaran Quantum Teaching mengintegrasikan totalitas fifik dan pikiran dalam proses pembelajaran.

\section{SIMPULAN}

Berdasarkan hasil pembahasan diatas yaitu: (1) Implementasi Quantum Teaching Pada Pembelajaran Tematik Kelas V di MI Mambaul Ulum Kandangrejo aspek kognitif yaitu peserta didik mampu berfikir secara lebih kritis dan luas, peserta didik mampu mengerjakan tugas atau latihan dan dapat memahami pembelajaran dengan baik, peserta didik mampu memberikan pertanyaan dan jawaban dengan baik dan sesuai. (2) Implementasi Quantum Teaching Pada Pembelajaran Tematik Kelas V di MI Mambaul Ulum Kandangrejo aspek dalam aspek afektif yaitu: rasa ingin 
tahu peserta didik meningkat, peserta didik menjadi lebih fokus, sikap peserta didik semakin percaya diri dan berani. (3) Implementasi Quantum Teaching Pada Pembelajaran Tematik Kelas V di MI Mambaul Ulum Kandangrejo aspek dalam aspek psikomotorik yaitu: peserta didik mampu mempraktikkan dengan baik media pembelajaran disediakan, peserta didik mampu menyebutkan nama dan bagian organ peredaran darah, peserta didik mampu menunjukkan bagian organ peredaran darah dengan menggunakan media.

\section{DAFTAR PUSTAKA}

DePorter, Bobbi dkk. Mempraktikkan Quantum Teaching di Ruang-Ruang Kelas. Bandung: Mizan Media Utama, 2008.

DePorter, Bobbi dkk. Mempraktikkan Quantum Teaching. Bandung: Kaifa, 2000.

Hamdani. Strategi Belajar Mengajar. Bandung: CV Pustaka Setia, 2011.

Nandang Kosasih dan Dede Sumana. Pembelajaran Quantum dan Optimalisasi Kecerdasan. Bandung: Alfabeta, 2013.

Observasi di Jember 24 September 2020.

Rahman, Taufiqur. Aplikasi Model-model Pembelajaran. Semarang: CV. Pilar Nusantara, 2018.

Rosyada, Dede. Penelitiian Kualitatif Untuk Ilmu Pendidikan. Jakarta: Kencana, 2020.

Sagala. Konsep dan Makna Pembelajaran. Bandung: Alfabeta. 2008.

Sekertariat Negara Republik Indonesia. Undang-Undang System Pendidikan Nasional. Jakarta: Sinar Grafika, 2016.

Sudjana, Nana. Dasar-Dasar Proses Belajar Mengajar. Bandung: SB Algensindo, 2019.

Sumining. "Pengembangan Bahan Ajar Tematik Berbasis Nilai-Nilai Keislaman Kelas VI Madrasah Ibtidaiyah". EDUCARE: Journal of Primary Education 2, no. 1 (2021).

Sunarti, Wawancara, Jember, 24 September 2020.

Tim Tashih Departemen Agama. Al-Qur'an dan Tafsirnya Jilid VII. Medan: PT Dana Bhakti Wakaf, 1995. 